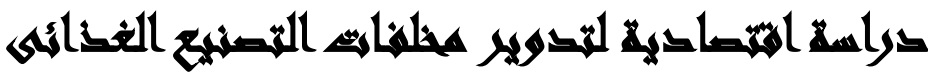

[V]

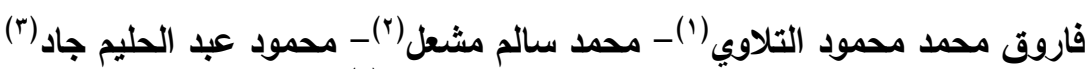

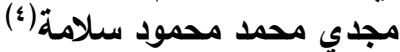

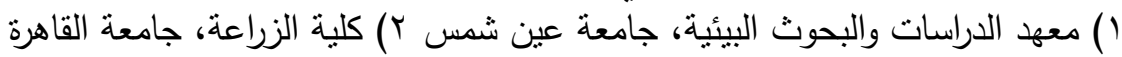

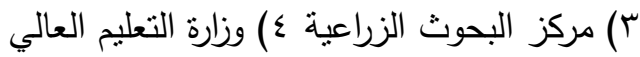

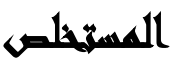

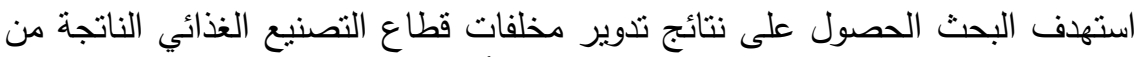

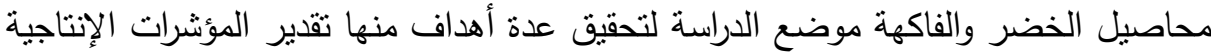

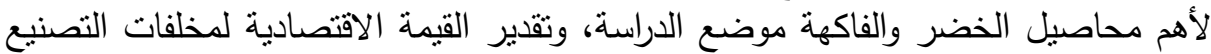

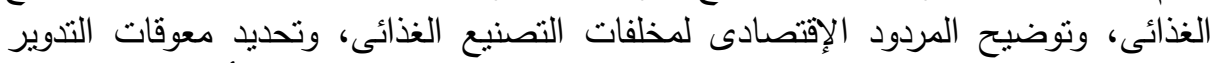

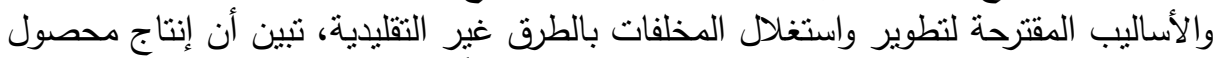

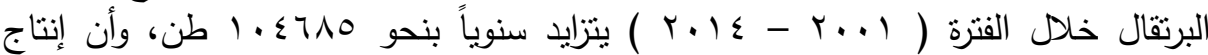

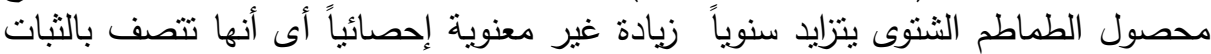

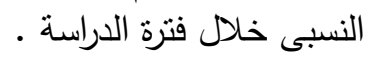

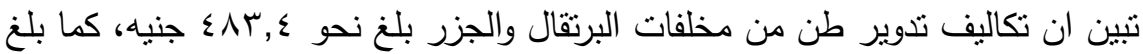

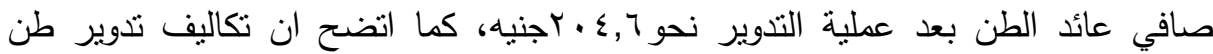

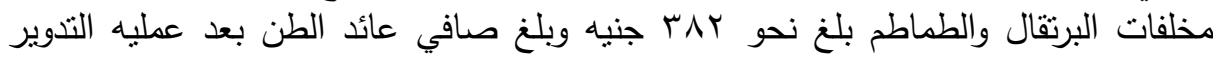

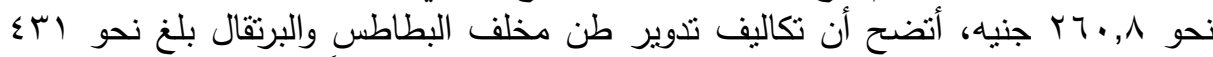

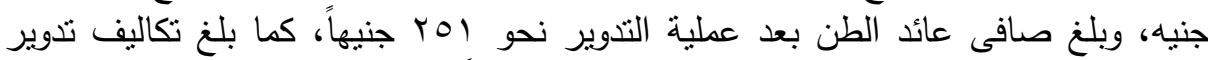

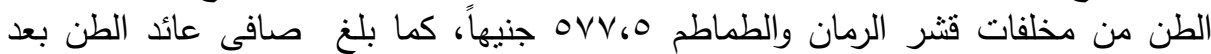

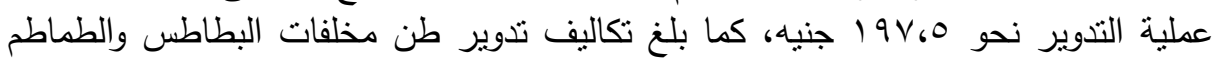

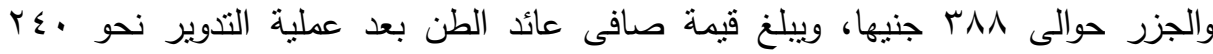
مفتاح الكلمات: تدوير مخلفات التصنيع الغذائى، صافى العائد، عائد الجنيه المستثر . 


\section{Xas}

يواجه العالم زيادة مستمرة فى الاحتياجات مع نقص المقابل للموارد مما يثير زيادة الاهتمام بإعادة استخدام المخلفات باعتبارها من الموارد المتجددة التي يمكن إعادة استخدامها بدلا من مجرد التخلص منها، ويجب النظر الى إدارة المخلفات والاستفادة منها فى إطار استراتيجية طويلة الأمد للمحافظة على الموارد الطبيعية من ناحية وللمحافظة على البيئة من ناحية أخرى، ولذا بدأ العالم فى نطوير الأساليب الإنتاجية المختلفة واستغلال كافة النواتج الثانوية الناتجة من الصناعات الغذائية، وتعتبر عملية تدوير مخلفات التصنيع الغذائى من أهم الهم

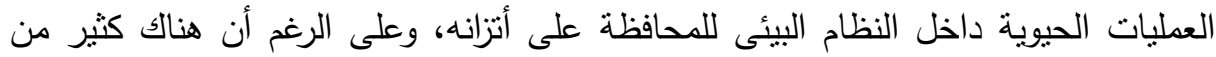
التباين فى مجالات إعادة الأستخدام والتدوير لمخلفات الفاكهة والخضر إلا أنها تتركز أساساً

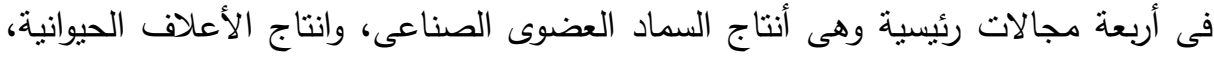
وإنتاج بروتين وحيد الخلية، وإنتاج مواد ذات قيمة اقتصادية وطاقة.

\section{rand}

تمنل مخلفات التصنيع الغذائي في مصر مشكلة كبيرة نظراً لكميتها الكبيرة، نتيجة

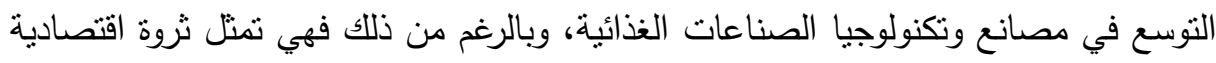
هائلة قادرة على تشغيل الثباب والطاقات المعطلة إذا ما تم توظيفها في منظومة منكاملة تتشمل مختلف النواحي الاقتصادية والاجتماعية والبيئية والفنية نظراً لما تحتويه هذه المخلفات

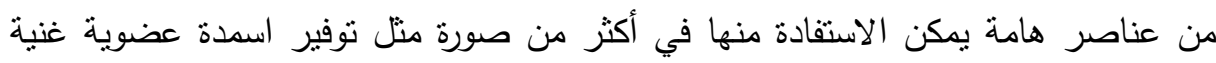
بالأحماض الأمينية، والتوسع في الزراعة العضوية وتوافر انواع غير تقليدية من الأعلاف،

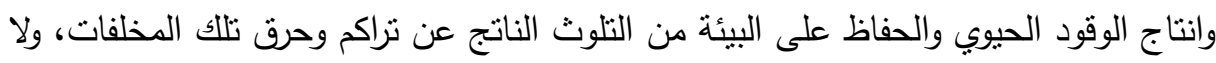
توجد رؤية واضحة للتعامل مع هذه المخلفات، مما يؤدى الى زيادة تلوث البيئة المحيطة وعدم الاستغلال الأمنل لهذه المخلفات. 


\section{أهساهثم الصراسة}

ا ـ تقدير المؤشرات الإنتاجية لأهم محاصيل الخضر والفاكهة موضع الدراسة .

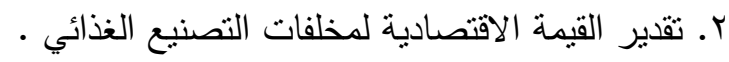
r. توضيح المردود الإقتصادى لمخلفات التصنيع الغذائي.

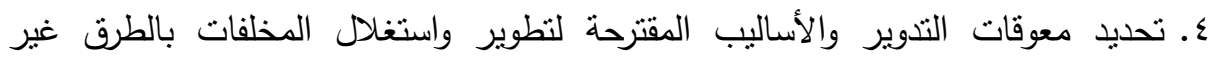

التقليدية.

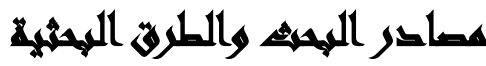

يعتد البحث على نوعين من البيانات، النوع الأول بيانات رسمية من جهات حكومية متل

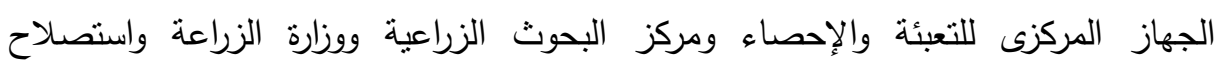

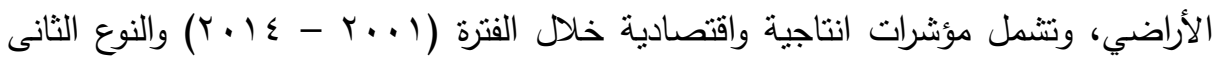

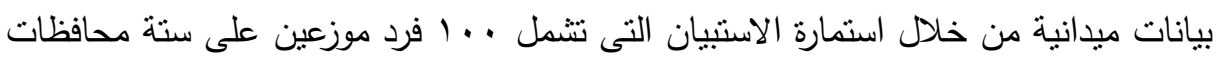

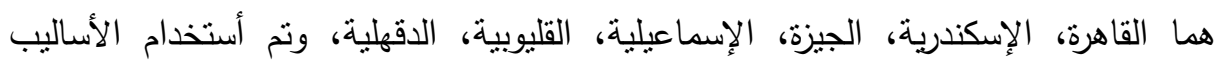
الإحصائية منل تحليل الأرتباط والإنحدار البسيط للسلاسل الزمنية للمؤشرات الإنتاجية لأهم محاصيل الخضر والفاكهة التى يتم تدوير مخلفاتها، بالإضافة الى أستخدام أسلوب التحليل

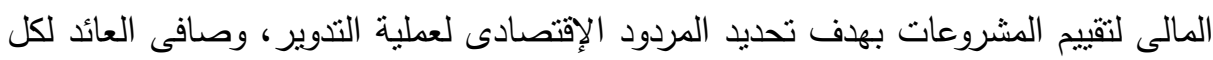

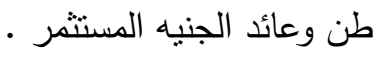

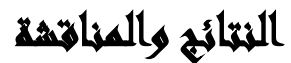

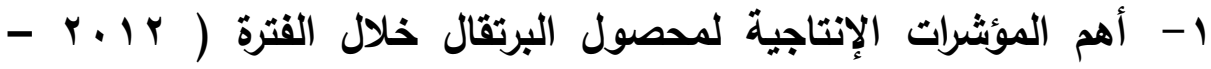
$:(r, 1 \varepsilon$

يوضح جدول (1) أهم المؤشرات الإنتاجية لمحصول البرتقال بمحافظات الجمهورية

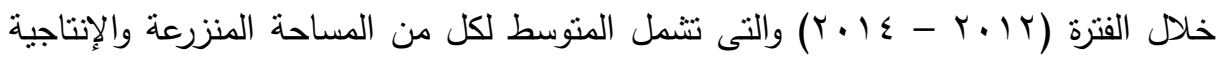

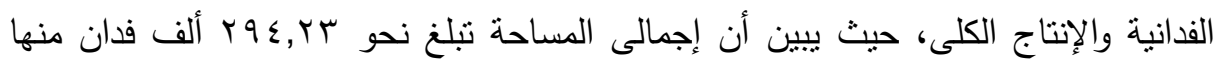

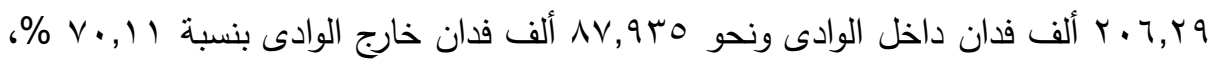




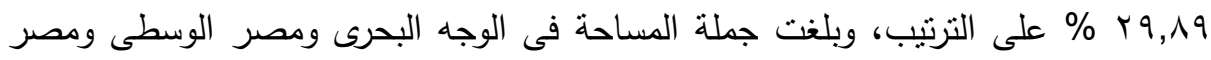

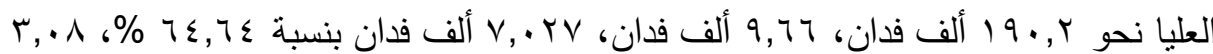

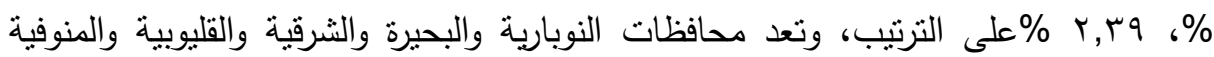
و الإسماعيلية أهم مناطق إنتاج محصول البرتقال فى مصر ، حيث تمثل مساحتها نحو

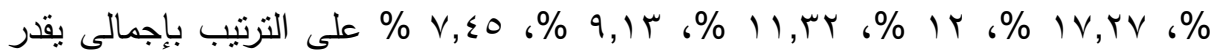
بنحو 10،10 \% من إجمالى مساحة الدحصول على مستوى الجمهورية، فى حين تمثل نسبة

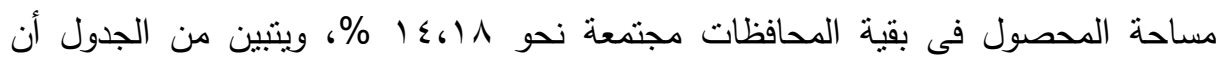

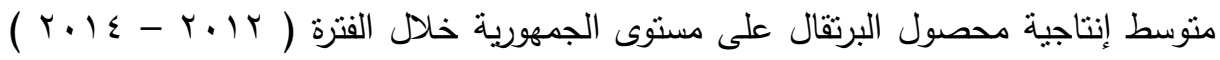

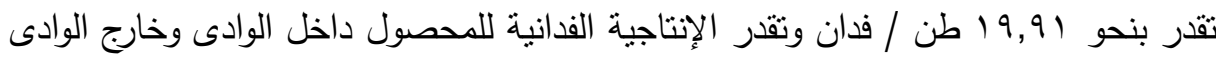

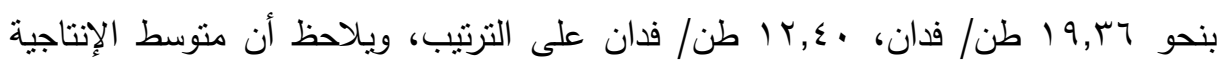

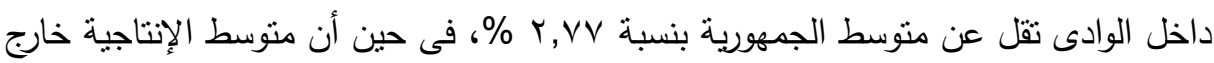

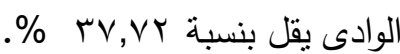

ينتين أن محافظات البحيرة وكفر الثيخ والإسماعيلية وأسيوط قد حققت إنتاجية أعلى من

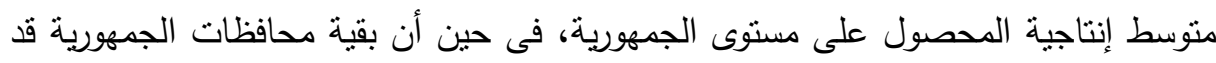
حققت إنتاجية أقل من متوسط الإنتاجية على مستوى الجمهورية، وأن إجمالى الإنتاج يبلغ نحو

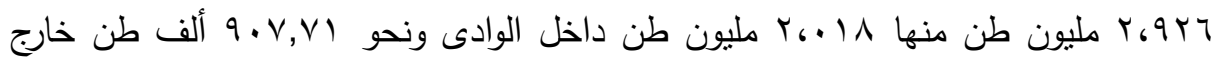

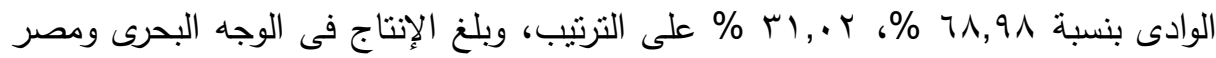

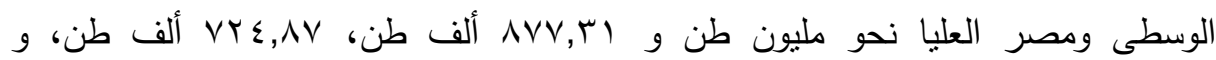

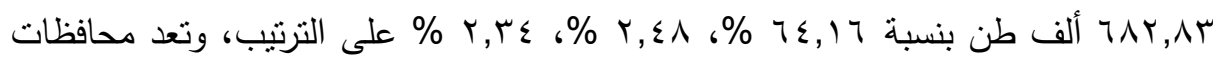

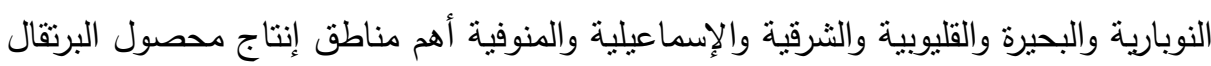

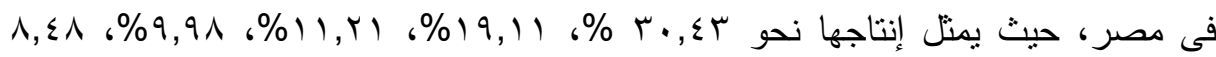

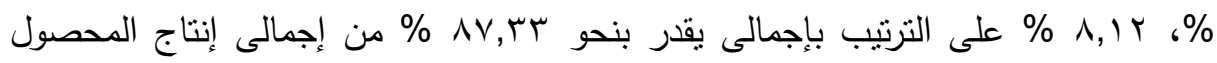
على مستوى الجمهورية، فى حين تمثل نسبة إنتاج المحصول فى بقية المحافظات مجتمعة

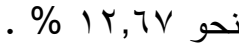

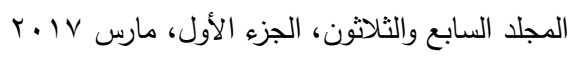


فاروق محمد محمود التلاوي وآخرون

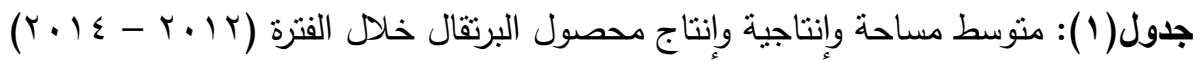

\begin{tabular}{|c|c|c|c|c|c|c|}
\hline المئوبية & الإنتاج & القباسمى & الإنتاجية متوسط & المئوية & متوسطة & المحافظات \\
\hline •.,YY & $70 V Y$ & $90, Y Y$ & 11,97 & •, YT & $7 \wedge \varepsilon$ & الإسكندرية \\
\hline 19,11 & 009111 & $1 \cdot \varepsilon, 9 V$ & $r \cdot, q$ & IV.YV & 0.1 .1 & ألبحيرة \\
\hline$r, \Sigma 1$ & $999 . Y$ & $\{7, \vee \backslash$ & $9, r$ & $r, 70$ & $1 \cdot V \varepsilon$. & الغربية \\
\hline $1, \Gamma \wedge$ & E. ro. & 11,10 & $r \varepsilon, 1 Y$ & $1,1 \leqslant$ & Tा & كفر الشيخ \\
\hline 1,01 & हा $\leqslant Y$ & $0 \leqslant, V \leqslant$ & $1 \cdot, 9$ & $1, \Gamma \wedge$ & $\varepsilon .77$ & الاقهلية \\
\hline . & YIV & $\Gamma 0, \Sigma\rceil$ & $V, \cdot T$ & $\cdot, \cdot 1$ & T & دمباط \\
\hline 9,91 & rq।人TV & $\Delta r, Y Y$ & $17,0 \mathrm{~V}$ & IT & rorqA & الثرقية \\
\hline$\Lambda, \Sigma \Lambda$ & $T \leqslant \lambda 100$ & $\| r, \lambda \mid$ & YY, §Y & $V, \leqslant 0$ & YI9YV & الإسماعيلية \\
\hline$\cdot, \cdots$ & Tr & $r 0,11$ & 0 & $\cdot, \cdots$ & 7 & بور سعيد \\
\hline$\cdot, V_{1}$ & $Y \cdot V \leqslant \Lambda$ & $09, V Y$ & 11,19 & $\cdot, 99$ & Yq) & السويس \\
\hline$\Lambda, I r$ & rTV09Y & $\Lambda \Gamma, \wedge \Lambda$ & $17, V$ & $9,1 T$ & 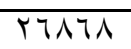 & المنوفية \\
\hline $11, Y 1$ & КイVАT & 91,19 & 19,00 & II, & דוחיז & القليوبية \\
\hline$\cdot, \cdot r$ & $V \leqslant 0$ & $r q, \vee \wedge$ & $V, 9 Y$ & $\cdot, \cdot V$ & Y. $\Sigma$ & القاهرة \\
\hline $7 \varepsilon, 17$ & IAVVM.V & $91, \cdot 9$ & 19,04 & $7 \varepsilon, 7 \varepsilon$ & $19.1 .$. & جملة الوجه البحري \\
\hline 1,10 & TrVTr & $V V, q$ & 10,01 & $1, \leqslant 9$ & $\varepsilon r V r$ & الجيزة \\
\hline$\cdot, 90$ & TVVAV & 91,77 & $1 \wedge, Y_{0}$ & $1, \cdot \varepsilon$ & r. & بني سويف \\
\hline$\cdot, 1 V$ & $\{971$ & rᄉ,OV & $\mathrm{V}, \mathrm{TA}$ & $\cdot, Y_{1}$ & $7 \leq 7$ & الفيوم \\
\hline$\cdot, Y_{1}$ & 7.7 & 71,04 & TY,YO & $\cdot, \Gamma \varepsilon$ & $9 \wedge \vee$ & المنيا \\
\hline$r, \Sigma \wedge$ & $V Y \leqslant \wedge V$ & $\vee \wedge, \wedge$ & 10,79 & $r, \cdot \Lambda$ & 9.77 & جملة مصر الوسطى \\
\hline 1,10 & or9ov & $|\cdot|, T_{1}$ & $T \cdot, I V$ & $1, V V$ & orrq & آسيوط \\
\hline • & NTqV & $\Lambda \cdot, \vee \backslash$ & $17, \cdot 1$ & $\cdot$, ro & $1.4 \Lambda$ & سوهاج \\
\hline$\cdot, .9$ & $1 \leqslant \mu \wedge$ & $70,1 \leq$ & $1 Y, 9 V$ & $\cdot, \cdot 1$ & YYY & قنا \\
\hline$\cdot, \cdots$ & $Y \sum Y Y$ & $V V, 19$ & 10,01 & $\cdot, 11$ & M. & الأقصر \\
\hline$\cdot, \cdot V$ & 4.79 & $\wedge \neg,\rceil \varepsilon$ & IV,YO & $\cdot, \cdot 1$ & TrV & أسوان \\
\hline$r, r \varepsilon$ & TAYAT & $90, \mathrm{VM}$ & $19,+7$ & $r, r q$ & $V \cdot Y V$ & جملة مصر العليا \\
\hline $7 \wedge, 9 \wedge$ & $r \cdot 11 . V T$ & $9 V, Y T$ & $19, r_{7}$ & $v \cdot, 11$ & r.7rqr & إجمالي داخل الوادي \\
\hline$\cdot, Y \xi$ & $T \wedge V Y$ & $r \wedge, 0 T$ & 0,71 & $\cdot, 77$ & 1941 & الوادي الجديد \\
\hline$\cdot, \cdot \leq$ & $1 \cdot \lambda r$ & $Y 1,00$ & $\varepsilon, Y q$ & $\cdot, .9$ & TOY & مطروح \\
\hline$\cdot, M r$ & 9470 & MY,00 & $7, \varepsilon \Lambda$ & $\cdot, \leqslant 9$ & $1 \leq \mu$. & شمال سيناء \\
\hline$\cdot, \cdots$ & $V \varepsilon$ & $|r, \Sigma|$ & Y,TV & $\cdot, \cdots$ & rA & جنوب سيناء \\
\hline$\Gamma \cdot, \varepsilon \Gamma$ & $\Lambda 9 \cdot \varepsilon 1 \Gamma$ & 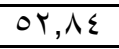 & $1 \cdot, 0 Y$ & YA,70 & ᄉ $\{Y q \leqslant$ & النوبارية \\
\hline$r, \cdot r$ & $q \cdot V V \cdot V$ & $T r, Y \wedge$ & $T Y, \varepsilon$ & $r q, \wedge q$ & AV9ro & إجمالي خارج الوادي \\
\hline $1 \ldots$ & YqYOVAr & $1 \ldots$ & 19,91 & $1 \ldots$ & YqEYYA & الجمهوربة \\
\hline
\end{tabular}

المصدر: جمعت وحسبت من بيانات وزارة الزراعة واستصلاح الأراضي، قطاع الثئون الاقتصادية، نشرة الإحصاءات الزراعية، أعداد مختلفة. 
الاتجاه الزمني العام لتطور أهم المؤثرات الإنتاجية لمحصول البرتقال خلال الفترة ( ب ... $:(r \cdot 1 \leqslant-$

يوضح جدول (Y) من خلا معادلة الاتجاه الزمني العام لنطور مساحة محصول

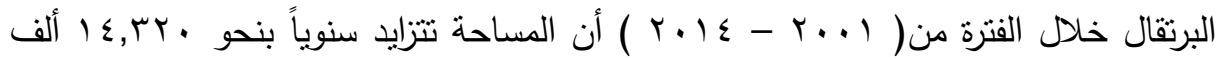

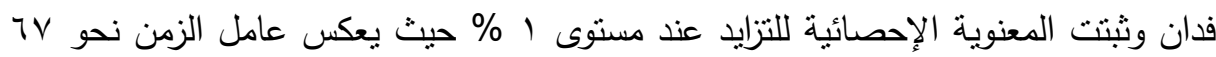
\% من إجمالي العوامل المؤثزة على المساحة خلال فترة الدراسة، ووتعير معادلة تطور إنتاجية

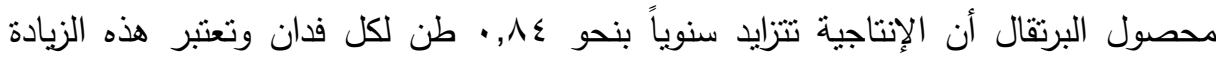

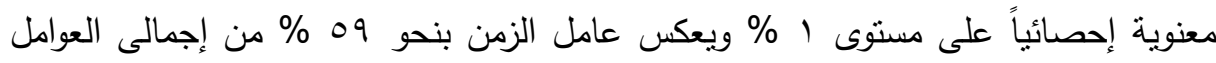

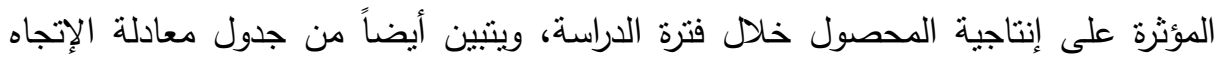

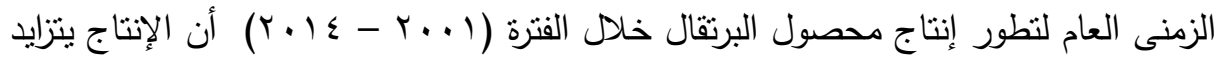
سنوياً بنحو عامل الزمن نمو ؟9 \% من إجمالى التغيرات فى إنتاج المحصول خلال فترة الدراسة .

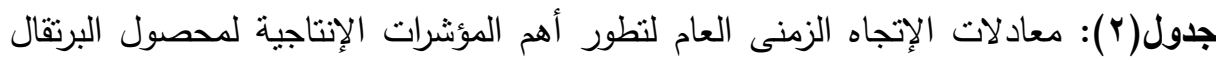

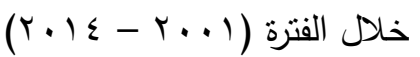

\begin{tabular}{|c|c|c|c|}
\hline$\overline{\mathbf{R}^{\prime}}$ & $\mathbf{R}$ & المعادلة & المؤشرات الإنتاجية \\
\hline 0.67 & 0.82 & 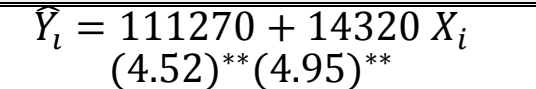 & 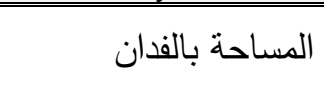 \\
\hline 0.59 & 0.77 & $\begin{array}{c}\widehat{Y}_{l}=5.51+0.841 X_{i} \\
(3.21)^{* *}(4.17)^{* *}\end{array}$ & الإنتاجية بالطن / الفدان \\
\hline 0.94 & 0.97 & $\begin{aligned} \widehat{Y}_{l}= & 1465182+104685 X_{i} \\
& (23.37)^{* *}(14.22)^{* *}\end{aligned}$ & ل طن \\
\hline
\end{tabular}

المصدر: حسب من بيانات وزارة الزراعة واستصلاح الأراضى، قطاع الثئون الإقتصادية، نشرة الإحصاءات الزراعية، أعداد مختلفة . 
تكاليف وعائد تذوير مخلفات البرتقال والجزر: يثير جدول ( r ) الى بنود تكاليف وعائد

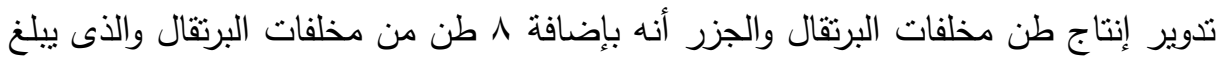

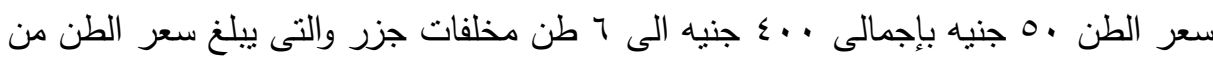

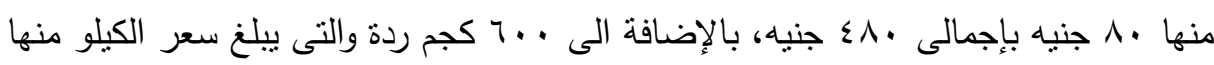

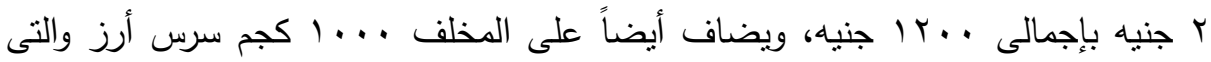

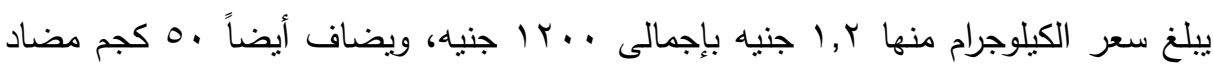

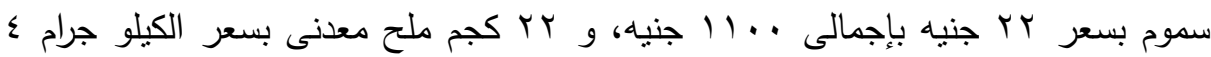
جنيه بإجمالى قدره M1 جنيه، كما يضاف . 10 كجم عيش بسعر الكيلوجرام 1,0 جنيه

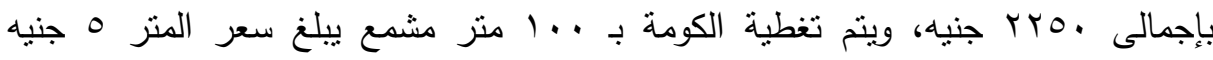

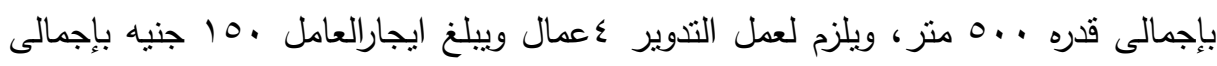

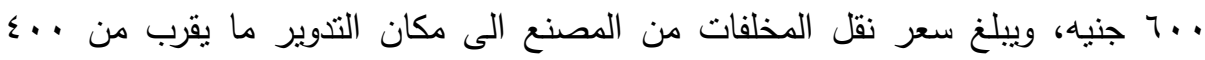

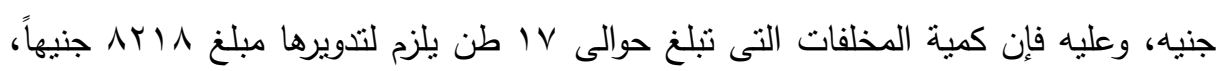

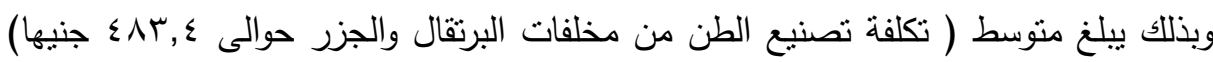

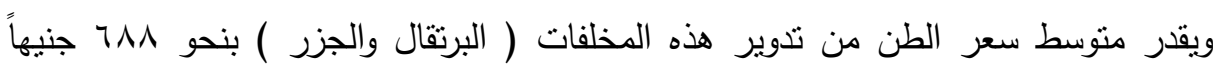

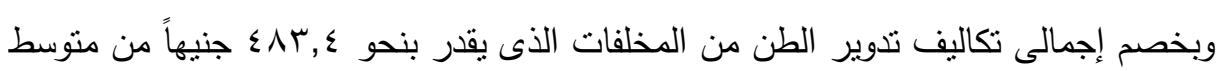

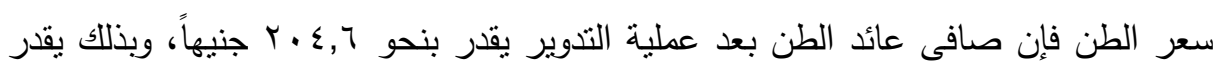

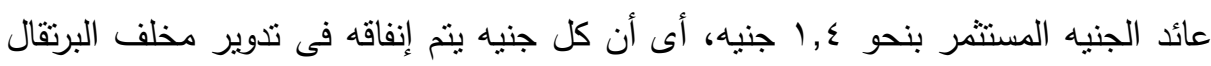

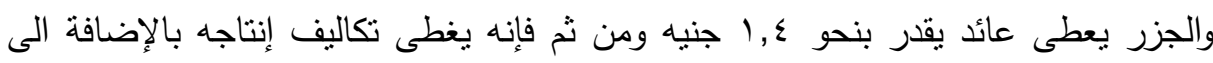
تحقيق صافى عائد يقدر بنحو ع , · جنيها للطن. 
مجلة العلوم البيئية

معهز الدراسات والبحوث البيئية - جامعة عين شمس لهن

جدول(ץ): تكلفة تدوير الطن من مخلفات البرتقال والجزر

\begin{tabular}{|c|c|c|c|c|}
\hline الثمن & سعرالوحدة & المخلف & الكمية & بنود التكاليف \\
\hline . . ع جنيه & .0 جنيه & مخلفات برتقال & א طن & 1 - نوع المخلف \\
\hline . & rجنيه & مخلفات جزر & 7 & ب - ثمن آية \\
\hline . . r| جنيه & r جنيه & & · . "דكجم & \\
\hline . . ب اجنيه & ب، 1 جنيه & سرس أرز & •... اكجم & على المخلف \\
\hline . . 11 جنيه & Y جنيه & مضاد السموم & مكجم & \\
\hline \ جنيه & ع جنيه & ملح معدنى & זrكجم & \\
\hline .0. جنيه & 0، 1، جنيه & عيش & • . 10 كجم & \\
\hline |. . جنيه & 0 جنيه & & ... امتز & \\
\hline$\cdots$ & جنيه & عمال & $\varepsilon$ & r-العمالة \\
\hline . . جـ جنيه & & & & ـكان التدوير النى \\
\hline 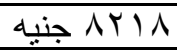 & & & اطن & الإجمالى \\
\hline & & & & متوسط سعر الطن \\
\hline T, • • Y جنيه & & & & صافى عائد الطن \\
\hline
\end{tabular}

المصدر : حسبت من بيانات استمارات الأستبيان

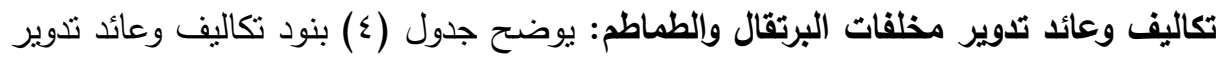

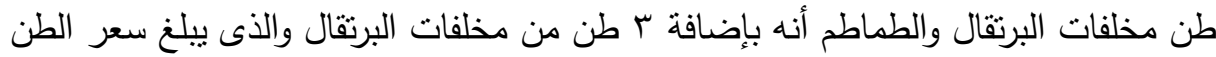
•0 جنيه بإجمالى .10 جنيه الى ب طن مخلفات الطماطم والتى يبلغ سعر الطن من منها

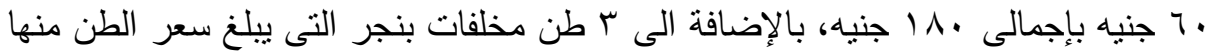

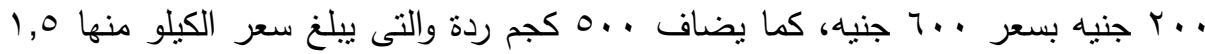

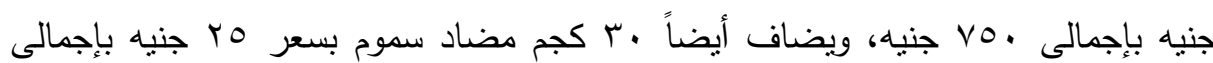
VO Pنيه، و O Y كجم ملح معدنى بسعر الكيلو جرام ؛ جنيه بإجمالى قدره ... جنيه، ويلزم لعمل التذوير ع عمال وييلغ ايجارالعامل .10 جنيه بإجمالى ..7 جنيه، ويبلغ سعر نقل المخلفات من المصنع الى مكان التدوير ما يقرب من . . ج جنيه، وعليه فإن كمية

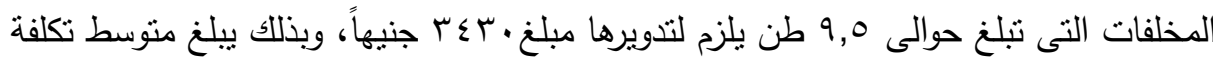
تصنيع الطن من مخلفات البرتقال والطماطم حوالى لبـ جنيها. 
كما يتبين أن متوسط سعر الطن من تدوير هذه المخلفات ( البرتقال والطماطم ) بنحو

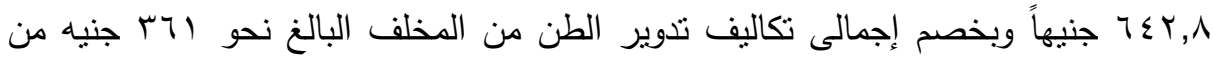

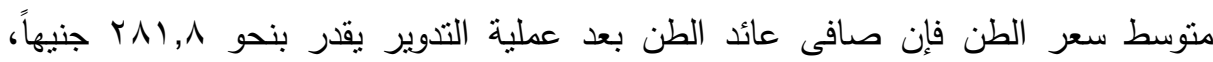

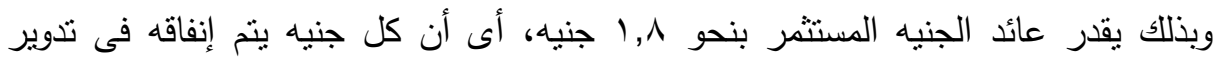
مخلف المانجو والبطاطس يعطى عائد يقدر بنحو ^,1 جنيه ومن ثم فإنه يغطى تكاليف

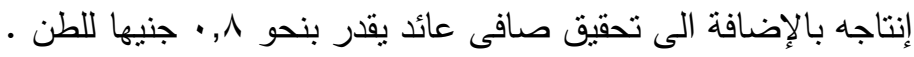
جدول( ؛): تكلفة تدوير الطن من مخلفات البرتقال والطماطم

\begin{tabular}{|c|c|c|c|c|}
\hline الثمن & سعرالوحدة & المخلف & الكمية & بنود التكاليف \\
\hline . 0 اجنيه & . 0 جنهـ & مخلفات برتقال & "rطن & 1- نوع المخلف \\
\hline 1/1 جنيه & الجنيه & مخلفات طماطم & ب ب طن & r- ثمن أية آضافات \\
\hline ل . اجنية & اجنيه . . . & بنجر & ك طن & تضاف علً المخلف \\
\hline V Vo. & 1، 1 جنيه & & . . مكجم & \\
\hline اجنيه & 0 & مضاد السموم & • سكجم & \\
\hline اجنيه . . (جيه & ك جنيه & ملح معدنى & ס זكجן & \\
\hline 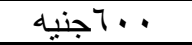 & 10. & عمال & $\varepsilon$ & r- العمالة وماتشمل \\
\hline ... & & & & ـ- النقل الى مكان التذوير \\
\hline . & & & مون 0 & الأجمالى \\
\hline 促 & & & & متوسط سعر الطن \\
\hline 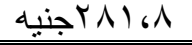 & & & & صافى عائد الطن \\
\hline
\end{tabular}

المصدر: حسبت من بيانات استمارات الاستبيان.

تكاليف وعائد تدوير مخلف البطاطس والبرتقال: يوضح جدول ( 0 ) بنود تكاليف وعائد

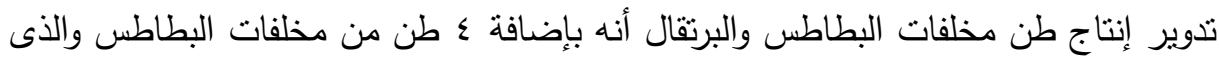

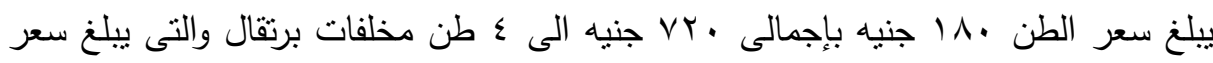

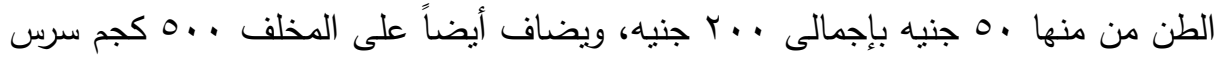

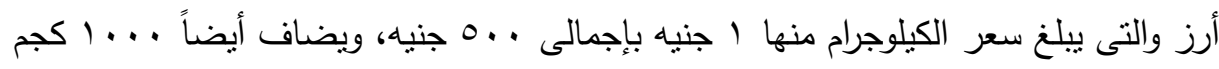

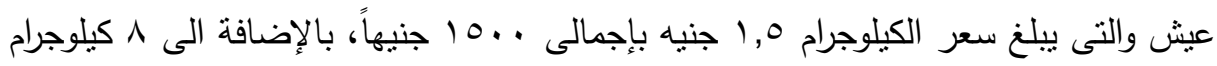

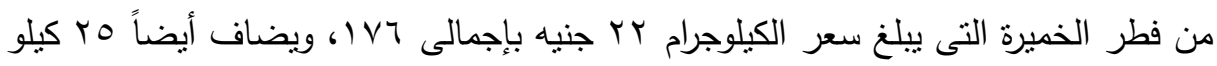

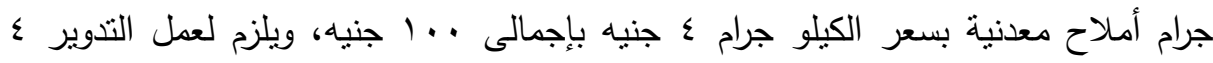

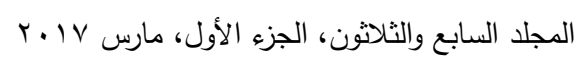


عمال ويبلغ ايجارالعامل .10 جنيه بإجمالى ..7 جنيه، ويبلغ سعر نقل المخلفات من

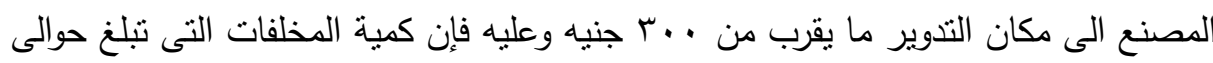

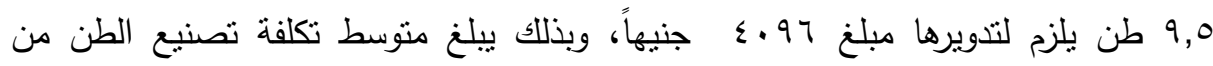
مخلفات البطاطس والبرتقال حوالى اسبـ جنيها، ويقدر منوسط سعر الطن من تدوير هذه

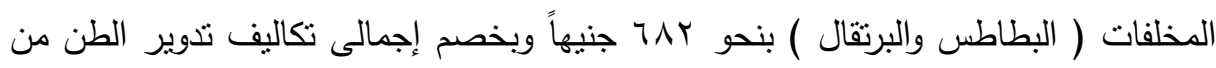
المخلف البالغ نحو ابـ جنيه من متوسط سعر الطن فإن صافى عائد الطن بعد عملية

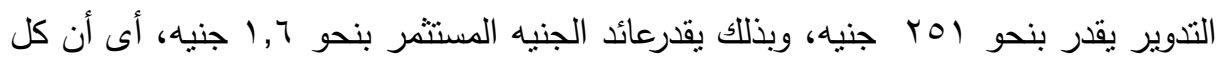

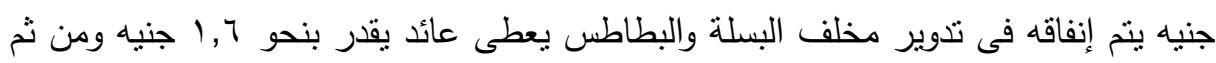
فإنه يغطى تكاليف إنتاجه بالإضافة الى تحقيق صافى عائد يقدر بنحو آب, بـ جنيها للطن. جدول(ه): تكلفة تدوير الطن من مخلفات البطاطس والبرتقال

\begin{tabular}{|c|c|c|c|c|}
\hline الثمن & سعرالوحدة & المخلف & الكمية & بنود التكاليف \\
\hline ك. Tنيه & . 11 جنيه & بطاطلفات & عطن & ا - نوع المخلف \\
\hline 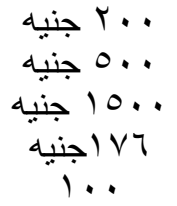 & 0. & فرلفات بيرتقال & 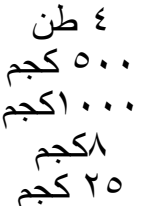 & تضاف عنى اية أضخافات \\
\hline أجنيه . . . & . 10 جنيه & عمال & $\varepsilon$ & " - العمالة وماتشمل \\
\hline ل ."اجنيه & & & & التدوبر النقل الى مكان \\
\hline جنيه 97 . & & & 0و، 0 & الأجمالي \\
\hline r Y T جنيه & & & & منوسط سعر الطن \\
\hline |01 جنيه & & & & صافى عائد الطن \\
\hline
\end{tabular}

المصدر : حسبت من بيانات استمارات الاستبيان 
r- أهم المؤشرات الإنتاجية لمحصول الطماطم الشتوى خلال القترة(r I • Y-

$(r \cdot 1 \varepsilon$

وضح جدول ( 7 ) أهم المؤشرات الإنتاجية لمحصول الطماطم الشتوى بمحافظات

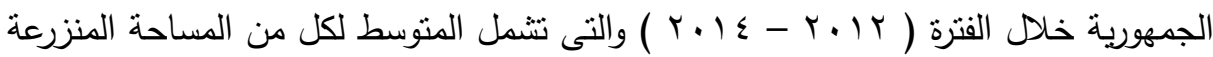

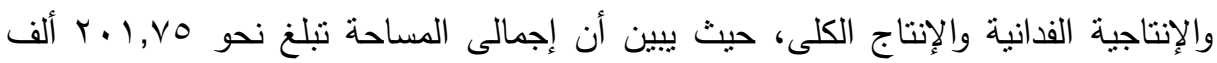

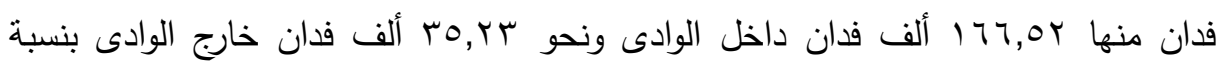

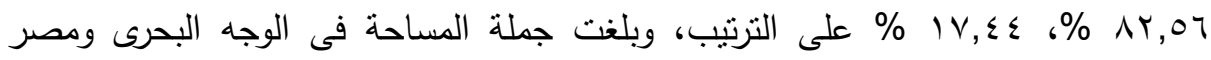

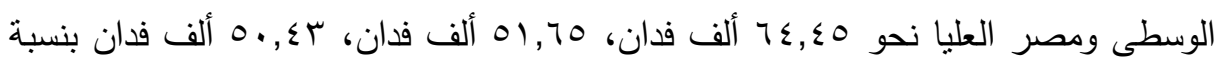

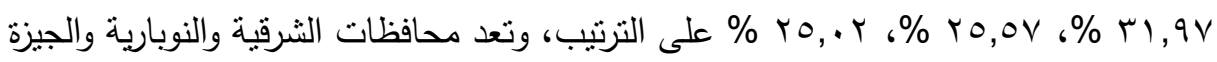

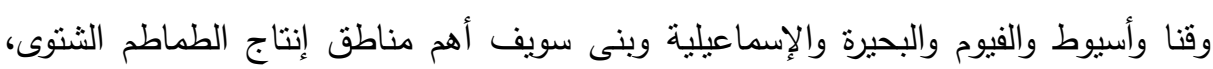

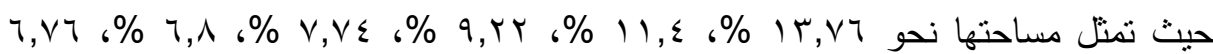

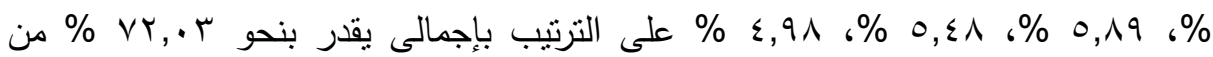
إجمالى مساحة المحصول، فى حين تمنل نسبة مساحة المحصول فى بقية المحافظات مجتمعة نحو YV,9V\% \% نجد أنه بالنسبة لإنتاجية محصول الطماطم الثتوى لمتوسط الفترة

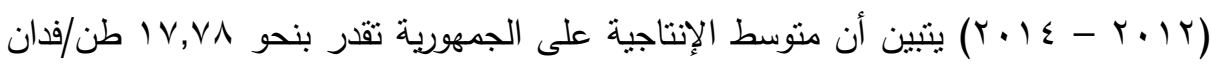

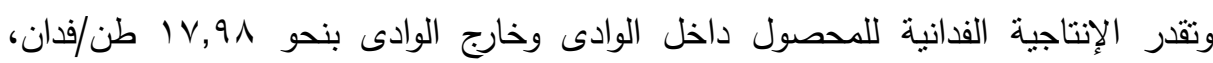

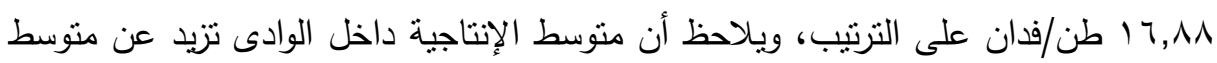

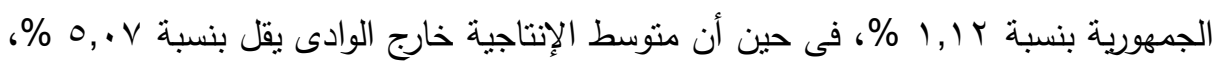

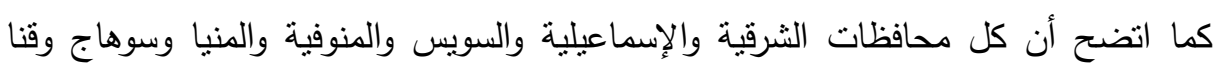

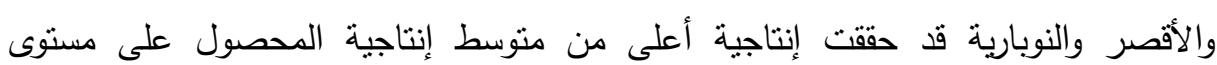
الجمهورية، فى حين أن بقية محافظات الجمهورية حققت إنتاجية أقل من منوسط الإنتاجية

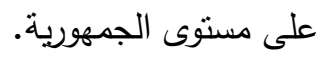




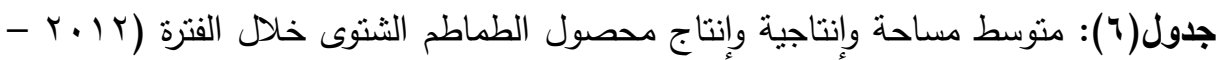

$(r \cdot) \leqslant$

\begin{tabular}{|c|c|c|c|c|c|c|}
\hline المئوبنة & الانتّاج & القياسق & الانتّاحسة & النسئة & المستاحة & المحافظات \\
\hline$\cdot, 11$ & $7 V 0 \xi$ & $\overline{V T, \cdot \varepsilon}$ & $|T, \Lambda|$ & $\cdot, Y 7$ & OPI & الإسكندرية \\
\hline$\varepsilon, 1 Y$ & $|\varepsilon \wedge| V \varepsilon$ & $79,1<$ & TY, E. & 0,19 & IINN & ألبحيرة \\
\hline$\cdot, \cdot V$ & $r V \cdot \Lambda$ & $0 V, 9 M$ & $1 \cdot, r \cdot$ & $\cdot, 1 T$ & rar & الغربية \\
\hline T,II & VOV7., & $\Lambda 0, \wedge \wedge$ & $10, Y V$ & $r, \varepsilon 7$ & ह9Vर & كفر الشبخ \\
\hline., $0 Y$ & $19 \cdots 7, V$ & $\varepsilon \Lambda, Y$. & $\Lambda, O V$ & $1, \cdot V$ & Y10 & الآدقهلية \\
\hline$\cdot, T T$ & ПNTA & Tq, Tr & $7, \leqslant \leqslant$ & $\cdot, 9 T$ & $\mid \wedge \leq 1$ & دمياط \\
\hline Tร,YO & 0111997 & $1.1,09$ & $\overline{1 \wedge, \Sigma Y}$ & IT,V7 & YVVIT & الشرقية \\
\hline 7,19 & rqVor7 & 101,91 & $Y V, \cdot 1$ & $0, \Sigma \Lambda$ & 11.7. & الإسماعيلية \\
\hline$\cdot, \cdot 0$ & 119. & Tᄉ, IT & $0, \cdots$ & $\cdot, 19$ & TVA & بوسعيد \\
\hline$\cdot, \mathrm{V \Lambda}$ & TA.0T & $1 \cdot, \wedge \varepsilon$ & $1 V, 9 T$ & $\cdot, \mathrm{Vq}$ & 107. & ألسويا \\
\hline$\cdot, \wedge \varepsilon$ & r. & $111, \lambda 1$ & $19, \wedge \wedge$ & $\cdot, 1 \times 7$ & IOYE & المنوفِية \\
\hline$\cdot, Y_{1}$ & קרז & $\wedge 9, \wedge \vee$ & 10,91 & $\cdot$, YO & $\varepsilon \vee \wedge$ & القليوبية \\
\hline$\bullet$ & $T \leqslant V$ & $O V, \Sigma T$ & $|\cdot, Y|$ & $\cdot, \cdot 1$ & To & القاهرة \\
\hline rq,V & আ & 99,77 & IV,VY & r , , qV & $7 \leq \varepsilon \leq 0$ & جملة الوجه البح \\
\hline$\Lambda, 0 \leq$ & TV.NT & 91,19 & 17,10 & $9, Y Y$ & 17711 & الجيزة \\
\hline$\varepsilon, 7 V$ & 178707 & $9 T, 7 \varepsilon$ & 17,70 & $\varepsilon, 91$ & $1 \cdot .71$ & بنى سويف \\
\hline$V_{6} V Y$ & КாАЯ & 10,70 & $10, Y T$ & 7,17 & 10709 & الفيوم \\
\hline$\varepsilon, V)$ & 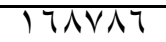 & $1 \cdot 9,19$ & $11,1 V$ & $\xi, 7)$ & $979 V$ & المنيا \\
\hline T0,7द & 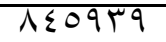 & $9 r, \cdot 1$ & 17,17 & TO,OV & $017 \leqslant V$ & الوسط \\
\hline $7, \pi$ & rYAYqI & $9 \mu, 01$ & $17,7 \leqslant$ & 7,1 & $1599 \mathrm{~V}$ & اسيوط \\
\hline$V, 9 V$ & rA091T & $10 \%, 91$ & TV,Y. & $0, Y I$ & 1.017 & سوهاج \\
\hline$\Lambda, 9 \vee$ & TYIVYE & 110,79 & $T \cdot, O V$ & $V, V \varepsilon$ & 107.7 & 官 \\
\hline$\varepsilon, 1 \wedge$ & $1 \leq 99 \leqslant V$ & $1 \cdot 0,71$ & $11, \vee 9$ & r,97 & V911 & الإقصر \\
\hline$\cdot, 7 r$ & TYTIT & $\varepsilon V, V$ & $1, \leqslant 9$ & $1, \Gamma$ & TIMT & اسوان \\
\hline TA, I & $1 \cdot . \wedge r \cdot \Lambda$ & $\prod r, \Sigma \Lambda$ & $T \cdot, \cdots$ & $T 0, \cdot T$ & $0 . \Sigma T T$ & جملة مصر العليا \\
\hline$\lambda \Gamma, \leqslant \Lambda$ & Y9907Yर & $1.1,1 Y$ & $1 V, 91$ & $\Lambda T, 0 T$ & $1770 Y \leqslant$ & إجماللي داخل الوادى \\
\hline$\cdot, 11$ & $\{171$ & $0 \cdot T \mu$ & 1,90 & $\cdot, Y T$ & $\varepsilon \leqslant 9$ & الوادى الجديد \\
\hline 1,19 & ร7ะาร & $7 \cdot, 7 T$ & $1 \cdot, \mathrm{VA}$ & $r, Y q$ & 2710 & مطروح \\
\hline$\cdot, \cdots$ & TT & $V, \varepsilon \wedge$ & Tוז, & $\cdot, \cdots$ & 7 & البحر الاحمر \\
\hline$T, 1 \varepsilon$ & V৭1V7 & 71,01 & $1 \cdot, 90$ & $\Gamma, \Sigma \Lambda$ & V.TL & شُكال سبناء \\
\hline$\cdot, \cdot \varepsilon$ & 1.71 & 01,70 & $9,0 \leqslant$ &., .0 & $\pi T$ & جنوب سيناء \\
\hline $17,9 \leq$ & 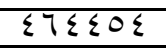 & $111, \leq 9$ & $r \cdot, 1 \wedge$ & $11, \varepsilon$ & YT. II & اللنوبارية \\
\hline 17,01 & 091.10 & $9 \varepsilon, 9 T$ & $17, \wedge \Lambda$ & $T V, \varepsilon \varepsilon$ & TOYYV & يى خارج الوادى \\
\hline $1 \cdots$ & ro1177T & $1 \cdots$ & $T V, V \wedge$ & $\cdots$ & r. IV0I & \\
\hline
\end{tabular}

المصدر: جمعت وحسبت من بيانات وزارة الزراعة واستصلاح الأراضي، قطاع الثشئون الاقتصادية، نشرة الإحصاءات الزراعية، أعداد مختلفة. 


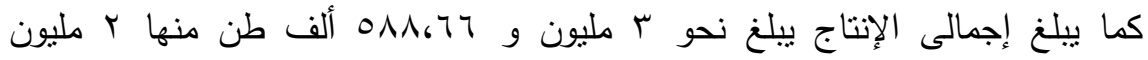

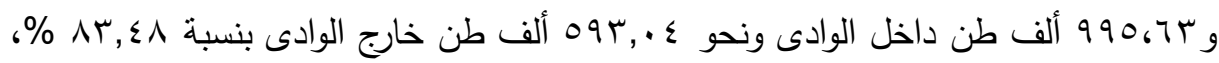

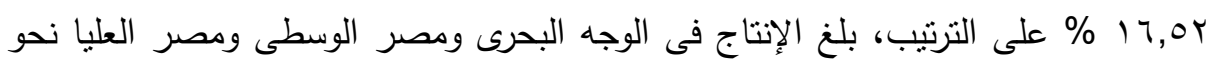

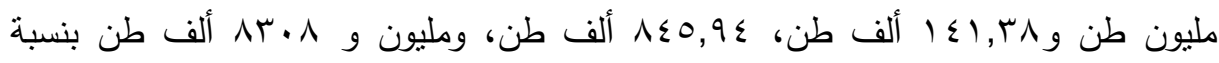

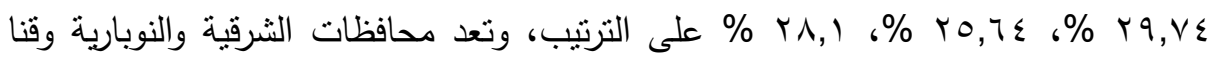

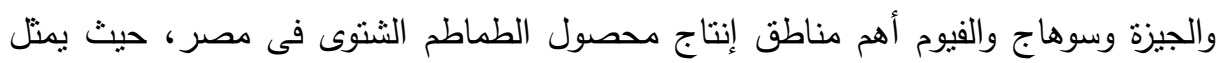

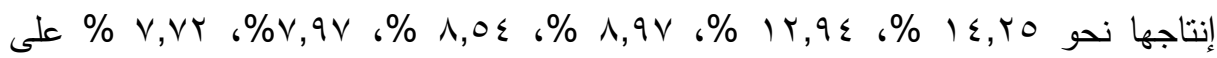

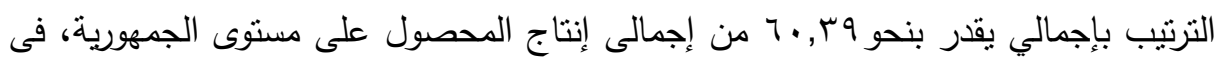

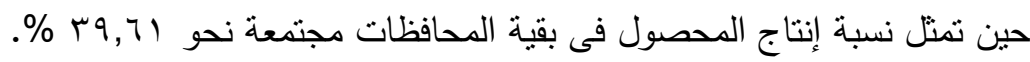
الاتجاه الزمني العام لتطور المؤشرات الإنتاجية لمحصول الطماطر الشتوى خلال الفترة $:(r \cdot 1 \leq-r \cdot 1)$ يوضح جدول ( V ) معادلة الإتجاه الزمنى العام لنطور مساحة محصول الطماطم

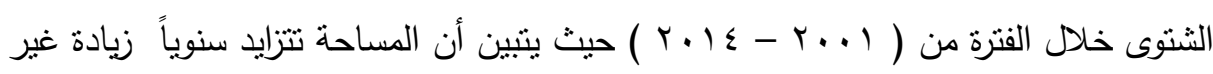
معنوية إحصائياً أى أنها نتصف بنالتبات النسبى خلال فترة الدراسة، كما ينضح أن إنتاجية

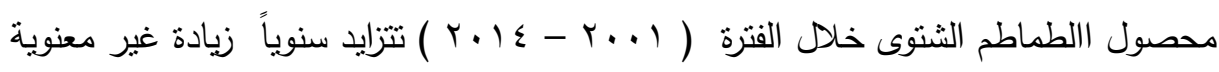

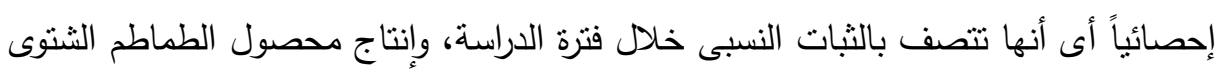

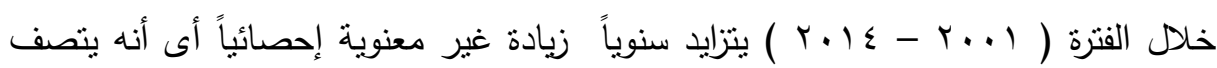
بالثبات النسبى خلال فترة الدراسة . 
جدول(V): معادلات الإتجاه الزمنى العام لتطور أهم المؤشرات الإنتاجية لمحصول الطماطم

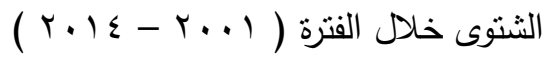

\begin{tabular}{|c|c|c|c|}
\hline$\overline{\mathrm{R}^{2}}$ & $\bar{R}$ & لمعادلة & المؤشرات الإنتاجية \\
\hline 0.22 & 0.47 & $\begin{array}{c}\widehat{Y}_{l}=181378+2797 X_{i} \\
(14.19)^{* *}(1.86)\end{array}$ & المساحة بالفدان \\
\hline 0.20 & 0.54 & $\begin{array}{c}\widehat{Y}_{l}=17.7+0.0198 X_{i} \\
(51.73)^{* *}(0.49)\end{array}$ & الإنتاجية بالطن / الفان \\
\hline 0.18 & 0.42 & $\begin{array}{c}\widehat{Y Y}_{l}=3220297+52317 X_{i} \\
(11.54)^{* *}(1.60)^{-}\end{array}$ & الإنتا \\
\hline
\end{tabular}

المصدر: حسب من بيانات وزارة الزراعة واستصلاح الأراضى، قطاع الثئون الإقتصادية، نشرة الإحصاءات الزراعية، أعداد مختفة

تكاليف وعائد تدوير قشر الرمان والطماطم: يوضح جدول ( ^ ) بنود تكاليف وعائد تدوير

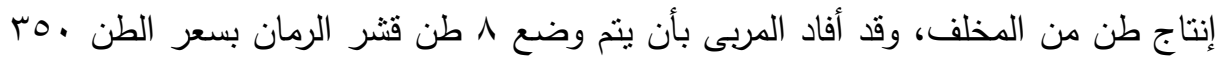

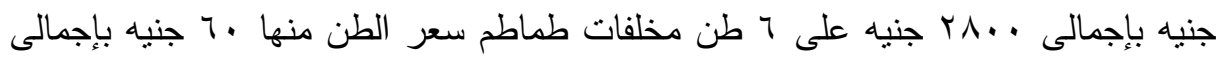

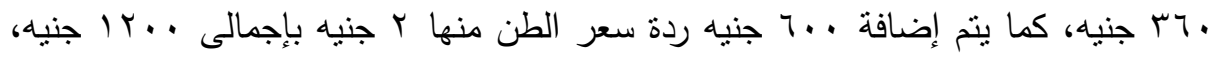

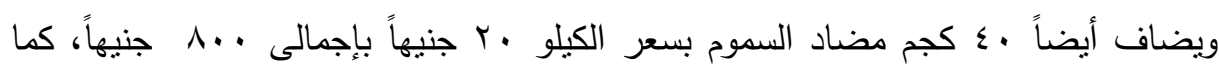

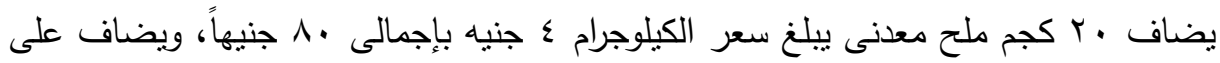

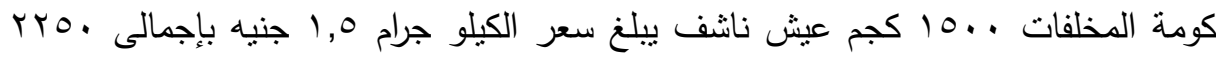

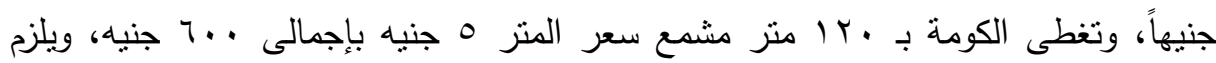

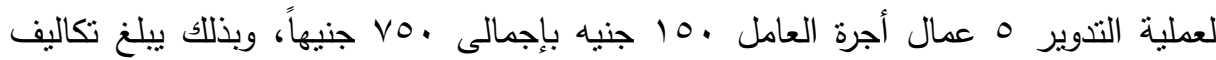

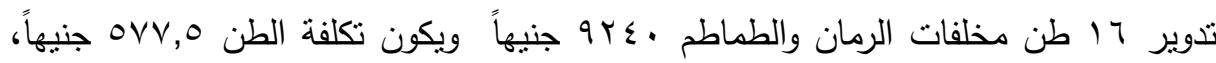

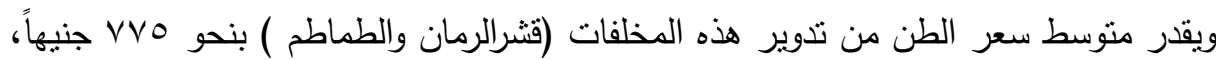
وبخصم إجمالى تكاليف تدوير الطن من المخلف الذى يبلغ نحو

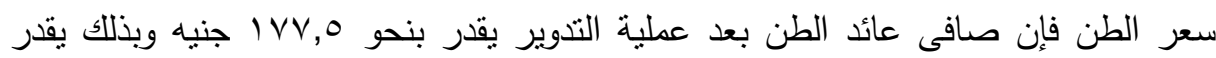

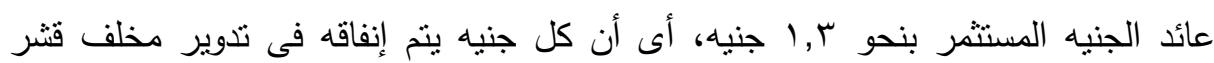
الرمان والطماطم يعطى عائد يقدر بنحو r, إنيه ومن ثم فإنه يغطى تكاليف إنتاجه بالإضافة الى تحقيق صافى عائد يقدر بنحو ب, · بعنيها للطن.

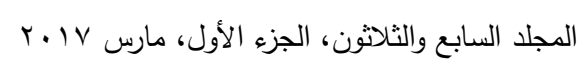


جدول(^): تكلفة تدوير الطن من مخلفات قثر الرمان والطماطم

\begin{tabular}{|c|c|c|c|c|}
\hline الثمن & سعرالوحدة & المخلف & الكمية & بنود التكاليف \\
\hline . . . & .0 جنيه & مخلفات قتشر & א طن & 1- نوع المخلف \\
\hline 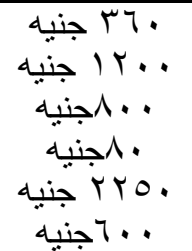 & 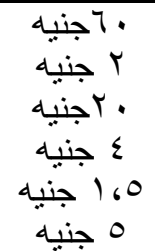 & مخلفات ملح ردماط السموم & 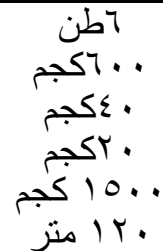 & على أضافات ثخلف تضاف \\
\hline ل0. جنيه & •lo جنيه & عمال & 0 & وماتشمل $\quad$ العمالة \\
\hline ل. جـ جنيه & & & & مكان التدوير \\
\hline . 9 ج 9 جنيه & & & 7 & الأجمالى \\
\hline Pنيه & & & & متوسط سعر الطن \\
\hline IVV,O جنيه & & & & صافى عائد الطن \\
\hline
\end{tabular}

المصدر : حسبت من بيانات استمارات الأستنيان ·

تكاليف وعائد تدوير مخلفات البطاطس والطماطم والجزر: يوضح جدول (9) بنود تكاليف وعائد تدوير إنتاج طن مخلفات البطاطس والطماطم والجزر أنه بإضافة r طن من مخلفات بطاطس والذى يبلغ سعر الطن •11 جنيه بإجمالى . بr جنيه الى ب طن مخلفات طماطم والتى يبلغ سعر الطن من منها .7 جنيه بإجمالى .11 جنيه، بالإضافة الى ع طن مخلفات

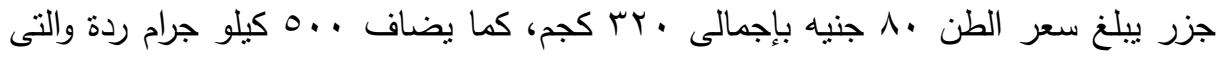

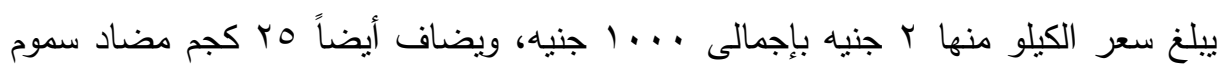

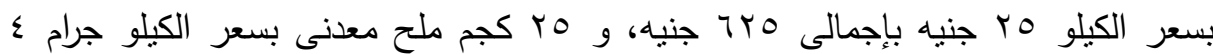

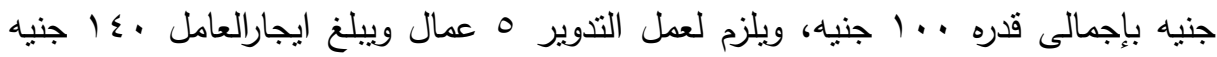

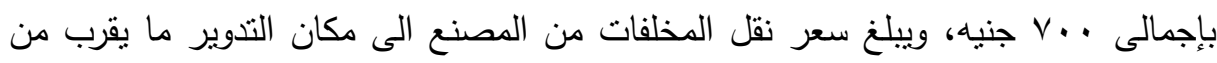

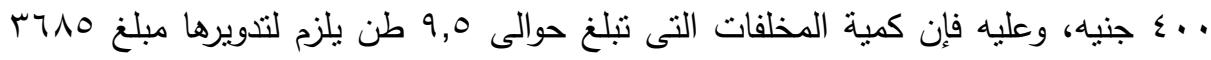
جنيهاً، وبذلك ييلغ متوسط تكلفة تصنيع الطن من مخلفات فثر البطاطس والطماطم والجزر

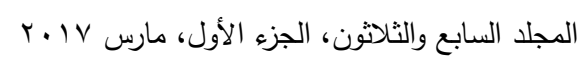


حوالى YNA جنيها، ويقدر متوسط سعر الطن من تدوير هذه المخلفات ( البطاطس والطماطم

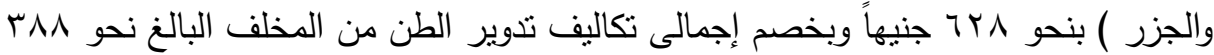

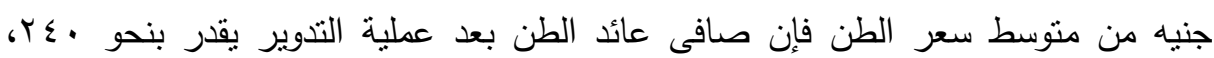
وبذلك يقدر عائد الجنيه المستثر بنحو 1,1 جنيه، أى أن كل جنيه يتم إنفاقه فى تدوير

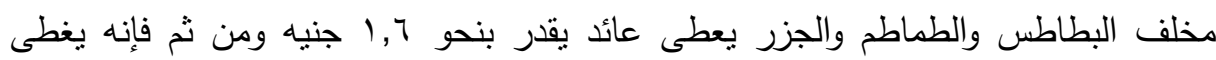
تكاليف إنتاجه بالإضافة الى تحقيق صافى عائد يقدر بنحو آ, · جنيها للطن. جدول(9): تكلفة تدوير الطن من مخلفات البطاطس والطماطم والجزر

\begin{tabular}{|c|c|c|c|c|}
\hline الثمن & سعرالوحدة & المخلف & الكمية & بنود التكاليف \\
\hline • ب"جنيه & . 1ا جنيه. & بطاطلفات & rطن r r r r & 1- نوع المخلف \\
\hline 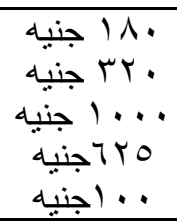 & 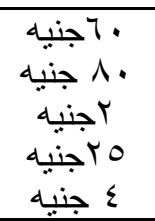 & 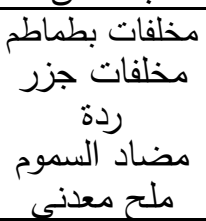 & 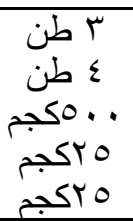 & أضافات ثلى تضاف أية \\
\hline ل . . جنيه & . ـ ا جنيه & عمال & 0 & وماتشمل \\
\hline . ع جنيه & & & & مكان التدوبر النقل الى \\
\hline & & & 0، 99طن & الأجمالى \\
\hline ג T T & & & & متوسط سعر الطن \\
\hline 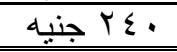 & & & & صافى عائد الطن \\
\hline
\end{tabular}

المصدر: حسبت من بيانات استمارات الاستبيان 
معوقات تدوير مخلفات التصنيع الغذائى والأساليب المقترحة لحلها:

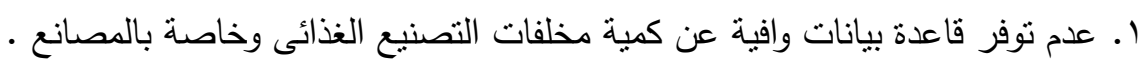
r. عدم قيام جهاز الإرشاد الزراعى بتوفير المرشدين لتوعية ودعم المزارعين بأهمية عملية تدوير المخلفات من أجل رفع مستواهم الإقتصادى والإجتماعى والبيئى، وتوفر بيئة خالية

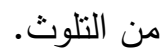
r. عدم وجود مصانع متخصصة تقوم بتدوير مخلفات التصنيع الغذائى، وعدم توفر الألات والتكنولوجيا الحديثة اللازمة لتدوير المخلفات . ع. تكوين العلائق غبر التقليدية لا زالت تتم بطريقة بدائية . مقترحات تطوير تدوير مخلفات التصنيع الغذائى: 1-قيام الدولة بتوافر بيانات إحصائية عن كمية ونوعية مخلفات التصنيع الغذائى ومواسم إنتاجها وتركيبها الكيماوى والقيمة الغذائية لهذه المخلفات.

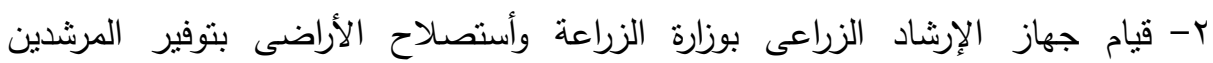

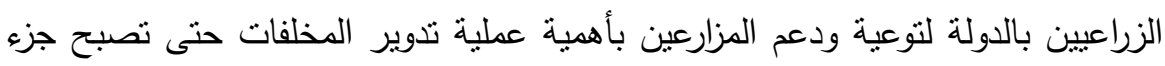
من سلوك المزارعين الإنتاجى من أجل رفع مستواهم الإقتصادى والإجنماعى والبيئى.

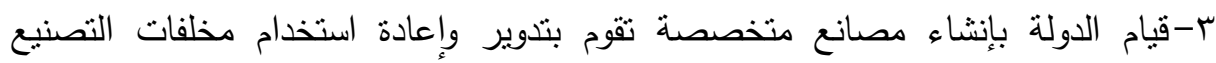
الغذائى فى كل المحافظات التى تتوفر بها كمية كبيرة من المخلفات، وتوفر الألات

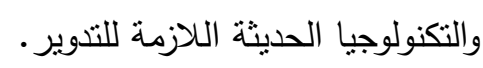
ع-تطوير تكوين العلائق غير التقليدية من مخلفات التصنيع الغذائى يشجع الاستثمار في مجالات التدوير ويخلق فرص عمل للثباب ويزيد من مستوى الدخل القومي ويحقق تتمية إقتصادية مستدامة، ويقضى على التلوث ويحسن من نوعية البيئة المصرية. 


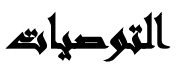

قيام الدولة بتوافر بيانات إحصائية عن كمية ونوعية مخلفات التصنيع الغذائى، وقيام

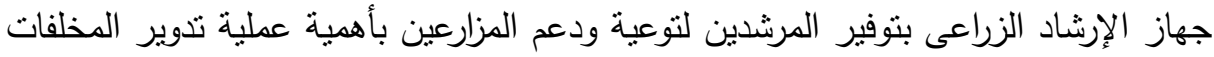

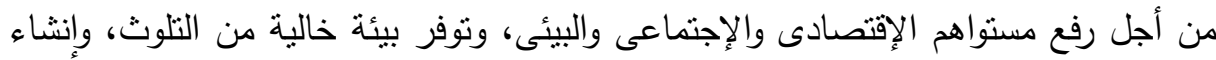
مصانع متخصصة تقوم بتدوير المخلفات بعد نوفر الألات والتكنولوجيا الحديثة، وقيام المراكز

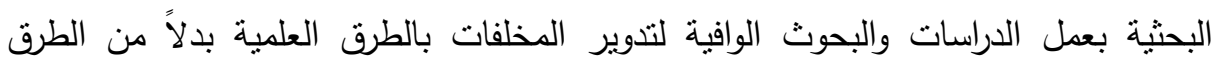
البدائية.

\section{المرايجr}

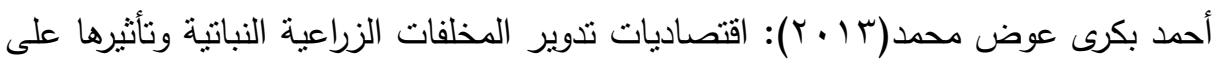
البيئة، رسالة دكتوراه، كلية الزراعة، جامعة القاهرة

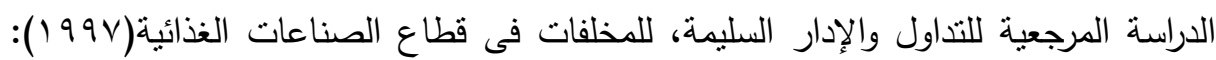
قطاع المجالس النوعية، وزارة الدولة لشئون البحث العلى العمى، أكاديمية البحث العلمى والتكنولوجيا

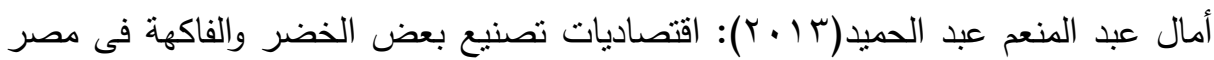

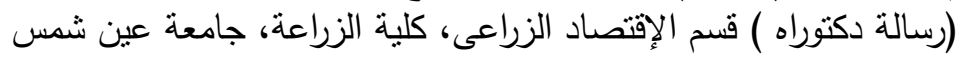

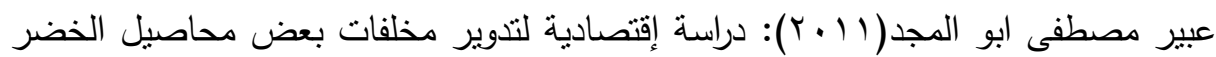
والفاكهة في مصر، رسالة دكتوراه، قسم الإقتصاد الزراعى، كلية الزراعة، لفاديل جامعة القاهرة

محمد السيد أرناؤوط(999)(199): طرق الإستفادة من المخلفات الزراعية، مكتبة الدار العربية للكتاب وزارة الزراعة واستصلاح الأراضى، قطاع الثئون الاقتصادية، نشرة الأحصاءات الزراعية،

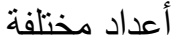


Carson, K .J.; J.L. Collins and M.P. Penfield (1994): Unrefined, Dried Apple Pomace as a Potential Food Ingredient. J. Food Sci $.59(6): 1213-1215$.

Edwards, P. W.; R. K. Eskew; A. Jr. Hoersch; N. C. Aceto and C. S. Redfield(1952): Recovery of tomato processing wastes. Food Technol., 6 :383-6.

EL-Nawawi ,S.A. and F.R. Shehata( 1987): Extraction of pectin from Egyptian orange peel . Factors affecting the extraction . Biological wastes ; 20 ( 4 ) : $281-290$ 
مجلة العلوم البيئية

معهذ الدراسات والبحوث البيئية - جامعة عين شمس البئ

\title{
AN ECONOMIC STUDY OF RECYCLING OF FOOD PROCESSING RESIDUES
}

\author{
El-Talawy, F. M. ${ }^{(1)}$; Meshal, M. S. ${ }^{(2)}$; Gad, M. A. ${ }^{(3)}$ \\ and Salama, M. M. M. ${ }^{(4)}$
}

1) Institute of Environmental Studies and Research, Ain Shams University 2) Faculty of Agriculture, Cairo University 3) Agricultural Research Center 4) Ministry of higher education

\begin{abstract}
This study drives at monitoring results of recycling of food processing sector of vegetables and fruits in order to achieve several targets including the estimation of productive indicators of the most important vegetables and fruits crops; estimating as well the economical value of food processing wastes, exposing also the economic outcome of these wastes and defining the obstacles of recycling and the proposed approaches for developing and utilizing wastes in untraditional methods. It is shown that the orange crop in the period (2001-2014) is annually increasing to be approximately 104685 tons and that the winter-tomato crops are also increasing but statistically insignificant.

Costs of manufacturing a ton of orange and carrot wastes is about 483.4 pounds, and the net revenue of one ton of recycling is 204.6 It is evident that costs of recycling a ton of orange and tomato are about 361 , while the net revenue after recycling is about 281.8 pounds. Processing of potato and orange wastes are 431 pounds and the net revenue after recycling is estimated by 251 pounds.. The manufacture of pomegranate peels and tomato is $\mathbf{5 7 7 . 5}$ pounds and the net revenue is 177.5 pounds.

The processing of potato, tomato, and carrot cost 388 pounds and the net revenue after recycling is about 240 pounds.
\end{abstract}

$$
\text { المجلد السابع والثلاثون، الجزء الأول، مارس VI. T }
$$


فاروق محمد محمود التلاوي وآخرون

Key Words: Recycling of Food Processing Residues - Net Profit Invested Pound Earning.

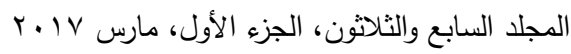

